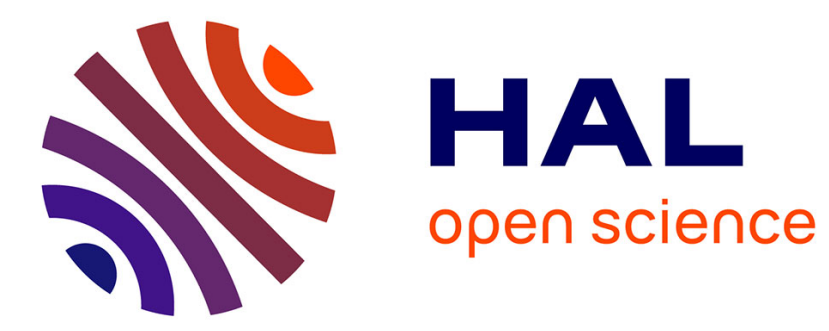

\title{
Targeted Lipidomics of Mycobacterial Lipids and Glycolipids
}

\author{
Emilie Layre
}

\section{To cite this version:}

Emilie Layre. Targeted Lipidomics of Mycobacterial Lipids and Glycolipids. Mycobacteria Protocols, 2314, Springer US, pp.549-577, 2021, Methods in Molecular Biology, 10.1007/978-1-0716-1460-0_24 . hal-03445430

\section{HAL Id: hal-03445430 \\ https://hal.science/hal-03445430}

Submitted on 26 Nov 2021

HAL is a multi-disciplinary open access archive for the deposit and dissemination of scientific research documents, whether they are published or not. The documents may come from teaching and research institutions in France or abroad, or from public or private research centers.
L'archive ouverte pluridisciplinaire HAL, est destinée au dépôt et à la diffusion de documents scientifiques de niveau recherche, publiés ou non, émanant des établissements d'enseignement et de recherche français ou étrangers, des laboratoires publics ou privés. 
Targeted lipidomics of mycobacterial lipids and glycolipids

Emilie Layre

Institut de Pharmacologie et de Biologie Structurale, Université de Toulouse, CNRS, Université Paul Sabatier, Toulouse, France.

emilie.layre@,ipbs.fr

\section{Running Head: Targeted lipidomics}

Keywords: Mycobacterium, lipidomics, mass spectrometry, HPLC-MS 


\begin{abstract}
Decades of study have highlighted the richness and uniqueness of the repertoire of lipid and glycolipid families produced by mycobacteria. Many of these families potently regulate host immune responses, in stimulatory or suppressive ways. Thus the global study of this repertoire in different genetic backgrounds or under model conditions of infection is gaining interest. Despite the difficulties associated with the specificities of this repertoire, the field of mass spectrometry-based lipidomics of mycobacteria has recently made considerable progress, particularly at the analytical level. There is still considerable scope for further progress, particularly with regard to the development of an efficient bioinfomatics pipeline for the analysis of the large datasets generated. This chapter describes an HPLC-MS methodology allowing the simultaneous screening of more than 20 of the lipid families produced by mycobacteria and provides recommendations to analyse the generated data given the state of the art.
\end{abstract}




\section{Introduction}

Different analytical techniques are used to analyse lipids and glycolipids including thin layer chromatography (TLC), nuclear magnetic resonance (NMR) and mass spectrometry (MS), which have their strengths and weaknesses, as previously reviewed [1]. Nevertheless, if by lipidomic we mean the rapid and "global" analysis of the lipids and glycolipids that characterise a given system, mass spectrometry appears to be the method of choice because it provides sensitivity, resolution, high throughput and allows assessing the acylforms diversity of the lipid families.

Lipidomics approaches, which have benefited from the enormous progress of mass spectrometry, are today diverse and highly developed, in particular for the analysis of eukaryotic lipids [2]. These approaches share main steps: i) sample preparation (lipid extraction), ii) analytical measurement (MS-based detection), iii) data processing (lipid identification and quantification) and iv) data interpretation, which depend on biological questions and rely on more or less complex bioinformatics pipelines. The type of samples (biological fluids, tissue or cell culture) and the "targeted" versus "untargeted" nature of the study condition these different steps. Whether the study focuses on certain lipid families of the lipidome (targeted study) or, on the contrary, on the lipidome in a global way with the possible discovery of new lipids (untargeted study), will lead to favour specific methods for lipid extraction and MS devices according to their performance in terms of sensitivity, dynamic range, and resolution.

Mycobacteria produce a very diverse and specific repertoire of alkyl chain-containing molecules including lipids and glycolipids [3], lipoproteins [4] and lipoglycans, which are potent immunomodulators with key roles in host-pathogen interactions [5,6]. These molecules distribute differently within the two membranes of the mycobacteria's envelope [7-10] (Fig. 1). The plasma membrane is mainly composed of phospholipids, phosphatidyl-myo-inositol di- and hexamannosylated ( $\mathrm{PIM}_{2}$ and $\mathrm{PIM}_{6}$ ), triglycerides (TAG), lipoproteins, and lipoarabinomanan (LAM). The outer membrane, or mycomembrane, is made of an inner leaflet composed of the mycolic acids (MA) (up to 90 carbon-long fatty acids) that are covalently bound to the arabinogalactan, itself linked to the peptidoglycan. In contrast, the outer leaflet of the mycomembrane is not covalently bound to the inner leaflet and encloses, besides the LAM and lipoproteins, an impressive diversity of unique lipid and glycolipid families as illustrated by a few examples in Figure 1. Among these surface lipidic components, mycolyl esters such as trehalose mono- and dimycolates (TMM and TDM) are found for all mycobacteria, with variation in their mycolic acyl groups (alpha, methoxy or keto mycolic acids). In contrast, 
phthiocerol dimycocerosate (PDIM), phenolic glycolipids (PGL) or sulfoglycolipids (SGL) are strain-specific lipid families. Each of these families exists as acylform variants, which number can reach several dozens. Finally, the bacillus surface is coated with a detergent-labile capsule layer essentially made of glycans and, to a lower extent, lipids and proteins [11]. Hence, similar to eukaryotes, mycobacteria also produce a repertoire of lipids that contains hundreds of molecular species [12].

Lipoproteins and lipoglycans, which are amphiphile macromolecules rather than lipids per se, are studied using specific extraction and analytical methods [13-16]. Hence, we will focus here on the so-called "extractible" mycobacterial lipids and glycolipids that are recovered by exposing mycobacteria pellets to organic solvents. This includes lipids from the cytoplasm, plasma membrane and outer leaflet of the mycomembrane. It is important to note that the mycolic acids of the mycomembrane's inner leaflet are not included in the extractible lipid pool. Indeed, in the absence of saponification to cleave their linkage with the arabinogalactan, they remain associated to the insoluble material after exposure of mycobacteria with organic solvents.

The purification and analysis by TLC of many of these lipid families have been widely described [17] and is also detailed in previous editions of this protocol book [18]. Mass spectrometry-based detection methods relying on the use of MALDI-Tof or ESI/APCI-MS instruments have also been used for the analysis of MA [19,20], SGL [21-23], DIM [22], PIMs [24-26,23], PGL[23], TMM [27] ,TDM [28] and siderophores (mycobactin and carboxymycobactin families) [29] and might be favoured for the specific high throughput analysis of one of these lipid family. More recently, lipidomic methods have been developed to analyse the M. tuberculosis lipid repertoire in a more global way. This effort has faced the challenges associated with the unique and structurally diverse mycobacterial lipids, which prevented the direct application of analytical methods developed for eukaryotic lipids. Two main studies have described HPLC-(ESI)-Q-Tof approaches that differ in the reverse phase (C18) [30] versus normal phase (diol) [12] chromatographic method. While the first one separates lipids based on their acyl groups (by acylform), the second one separates lipids based on their polar head (by family), but both approaches provide a wide coverage of $M$. tuberculosis lipidome. Both studies also released a theoretical database listing the calculated $\mathrm{m} / \mathrm{z}$ of adducts of the published M. tuberculosis lipid families, called Mtb LipidDB (https://mrl.colostate.edu/mtb/) [30] and MycoMass (https://www.brighamandwomens.org/research/departments/rheumatology-immunologyallergy/moody-lab/overview) [12], respectively. 
If the M. tuberculosis lipidomic field has made significant progress it lags behind the lipidomics of eukaryotic lipids because it still suffers from several shortcomings: the lack of a MS/MS database that would allow Multiple Reaction Monitoring mode analysis for the identification of lipids, the poor availability of standards to achieve absolute quantification, and the lack of a straightforward bioinformatics pipeline for high-throughput data analysis, especially for unbiased and comparative analysis of large number of datasets.

Based on the previously published method that relies on diol chromatography coupled to (ESI)-MS [12], this chapter describes a lipidomic approach to perform the simultaneous screening of more than 20 of the main M. tuberculosis lipid families. This method has been successfully used in the past to characterise M. tuberculosis lipid profile in response to stress [31], to compare the lipid profile of mycobacteria strains [32] and also to detect mycobacterial lipid in tissues [32]. The mass spectrometer available in the environment of a given laboratory is a limiting and inflexible factor, given the cost of such an instrument. Thus, the parts of this chapter describing the analytical detection of mycobacterial lipids and the data analysis correspond to recommendations to implement this approach and ensure quality of the analyses rather than a wet-lab protocol.

\section{Material}

\subsection{Glycolipid extraction from mycobacteria culture}

1. Chemical fume hood

2. LC-MS-grade chloroform $\left(\mathrm{CHCl}_{3}\right)$ or dichloromethane $\left(\mathrm{CH}_{2} \mathrm{Cl}_{2}\right)$ (see Note 1)

3. LC-MS-grade methanol $\left(\mathrm{CH}_{3} \mathrm{OH}\right)$

4. LC-MS-grade water.

5. Solvent evaporation system: centrifugal evaporator, Genevac or nitrogen stream

6. $50 \mathrm{~mL}$ polypropylene $\mathrm{V}$-bottom tubes (Falcon type)

7. $50 \mathrm{~mL}$ screw centrifuge glass tubes (Pyrex quality) with PTFE coated screw caps

8. $250 \mathrm{~mL}$ round bottom flasks if using rotary vacuum evaporator as drying system or $15 \mathrm{~mL}$-glass tubes if using stream-drying system to dry organic phases. 
9. $500 \mu \mathrm{L}$ Hamilton syringes

10. Pasteur glass pipettes

11. Rocking shaker

12. Nitrogen stream drying system

13. Microbalance

14. 2 mL-amber vials with PTFE screw caps

\subsection{HPLC-MS analysis}

1. LC-MS-grade hexane, 2-isopropanol, methanol, formic acid $\left(\mathrm{CH}_{3} \mathrm{COOH}\right)$ and ammonium hydroxide $\left(\mathrm{NH}_{4} \mathrm{OH}\right)$

2. Solvent A: 70:30 hexane : isopropanol (v :v), 0.1\% (v/v) formic acid, 0.05\% (v/v) Ammonium hydroxide

3. Solvent B: 30:70 methanol : isopropanol, 0.1\% (v/v) formic acid, 0.05\% (v/v) Ammonium hydroxide

4. Diol (dihydroxypropyl group bonded phase) HPLC column ( $150 \mathrm{~mm} \times 2 \mathrm{~mm}, 3 \mu \mathrm{m}$ particles of $10 \AA$ A porosity) and a Diol guard column (3 $\mu \mathrm{m} \times 4.6 \mathrm{~mm})($ see Note 2$)$.

5. High-resolution mass spectrometer (see Note 3).

\subsection{Targeted screening and comparative analysis}

1. R software

2. msConvert ProteoWizard

3. MS database: Mtb LipidDB [30] (https://mrl.colostate.edu/mtb/) or MycoMass [12] (https://www.brighamandwomens.org/research/departments/rheumatology-immunology-allergy/moody-lab/overview)

\section{Methods}

\subsection{Glycolipid extraction from mycobacteria culture}


1. Transfer $50 \mathrm{~mL}$ of mycobacterial culture grown in the absence of detergent (see Note 4) into 50 mL polypropylene V-bottom tubes.

2. Centrifuge the tubes at $2000 \mathrm{~g}$ for $15 \mathrm{~min}$ at room temperature and discard the supernatant.

3. Wash the pellet twice with $10 \mathrm{~mL}$ of water by resuspending the bacteria and repeating step 2 .

4. Resuspend the bacterial pellet in $1 \mathrm{~mL}$ of methanol.

5. Add internal lipid standard (see Note 5).

6. Transfer the methanolic bacterial suspension to $50 \mathrm{~mL}$ screw centrifuge glass tubes with PTFE coated screw caps containing $45 \mathrm{~mL}$ of $1: 2$ chloroform:methanol ( $\mathrm{v}: \mathrm{v})$ (see Note 6).

7. Allow sterilisation overnight (see Note 7).

8. Shake tubes on a rocking shaker for about $1 \mathrm{~h}$.

9. Pellet the bacteria at $2000 \mathrm{~g}$ for $15 \mathrm{~min}$ (or until a translucent supernatant is obtained), at room temperature.

10. Transfer and dry the supernatant in clean $250 \mathrm{~mL}$-round bottom flask or in $15 \mathrm{~mL}$-glass tubes depending on available evaporating system.

11. Resuspend the pellets in $45 \mathrm{~mL}$ of 1:1 chloroform:methanol (v:v) and repeat steps 8-10. Pool the organic supernatants.

12. Resuspend the pellets in $45 \mathrm{~mL}$ of $2: 1$ chloroform:methanol (v:v) and repeat steps 8-10. Pool the organic supernatants.

13. Dry the pooled organic supernatants using a centrifugal evaporator, gene-vac or under nitrogen stream in a chemical hood.

14. Resuspend the dried lipids in $1 \mathrm{~mL}$ of 1:1 chloroform:methanol (v:v), transfer to a pre-weighted $2 \mathrm{~mL}$-amber glass vial with a Hamilton syringe and dry under a gentle nitrogen stream without heat.

15. Rinse with additional $1 \mathrm{~mL}$ of $1: 1$ chloroform:methanol (v:v), add to the $2 \mathrm{~mL}$-amber glass vial with a Hamilton syringe and dry under a gentle nitrogen stream without heat.

16. Weight the dry lipids (see Note 8), resuspend at $2 \mathrm{mg} / \mathrm{mL}$ in $1: 1$ chloroform:methanol (v:v), store at $-80^{\circ} \mathrm{C}$ if not analysed immediately (see Notes 9). 


\subsection{HPLC-MS analysis}

\section{2.a Set-up of the HPLC-MS system for targeted screening of mycobacterial lipids}

1. Equilibrate the HPLC Diol column at room temperature with Solvent A at $0.15 \mathrm{~mL} / \mathrm{min}$ for $30 \mathrm{~min}$ (see Note 10).

2. Establish the (m/z, RT) map of the lipid families of interest using your HPLC-MS instrument (see Note 11):

- Inject purified/synthetic M. tuberculosis lipids (see Note 12) or reference M. tuberculosis lipid extract and apply the following gradient at room temperature and at a flow rate of $0.150 \mathrm{~mL} / \mathrm{min}$ as follows (see Note 13) :

\begin{tabular}{l|l}
\hline Time (min) & $A / B(\%)$ \\
\hline 0.0 & $100 / 0$ \\
10.0 & $100 / 0$ \\
17.0 & $50 / 50$ \\
22.0 & $50 / 50$ \\
30.0 & $0 / 100$ \\
35.0 & $0 / 100$ \\
40.0 & $100 / 0$ \\
44.0 & $100 / 0$ \\
\hline
\end{tabular}

- Map the respective M. tuberculosis lipids MS signals in your system. In the absence of MS/MS database, the assignment of MS signals to given lipid families relies on the validation of at least 2 of following criteria: 
The lipids are detected at $\mathrm{m} / \mathrm{z}$ matching the calculated $\mathrm{m} / \mathrm{z}$ within the mass accuracy of the high-resolution mass spectrometer (as low as 1 ppm and never exceeding 10 ppm mass accuracy) and show the expected acylform profile when analysing purified lipid family or total lipid extract (see Note 14).

Observed retention time matches the retention time of standard (when available), i.e. synthetic or purified acylform of the lipid family (see Note 12).

The fragmentation pattern obtained by MS/MS confirms the building blocks that characterise the lipid family (see Note 15 ).

Table 1 lists the characteristics of the MS signal of the lipid families detected analysing the M. tuberculosis H37Rv lipid extract using the Diol HPLC-Agilent 6520 Accurate-Mass Q-Tof.

3. Ensure reproducibility and stability over time of the assigned MS signals by performing multiple and consecutive analyses of the same $M$. tuberculosis lipid extract. Alternate with blank runs (injection of 1:1 chloroform:methanol (v:v) or solvent A) to confirm absence of detection of carryover during the blank runs.

4. Store aliquots of the mycobacterial lipid mixture (purified/synthetic mycobacterial lipids or natural lipid extract) used for parameters optimisation and the associated datasets to control the response of the mass spectrometer before a new experiment and after mass spectrometer maintenance.

\section{2.b Perform targeted screening of mycobacterial lipids in lipid extract of interest}

1. Equilibrate the HPLC-MS diol column at room temperature with Solvent A at $0.15 \mathrm{~mL} / \mathrm{min}$ for 30 min (see Note 10).

2. Ensure the cleanliness and the proper functioning of the system by analysing an alternation of blank samples (solvent used to solubilise the samples, see subheading 3.1 step 14) and lipid reference samples using the gradient described above (subheading 3.2.a, step 2). 
3. Inject 10-20 $\mu \mathrm{g}$ of the lipid extract of interest resuspended in 10-20 $\mu \mathrm{L}$ of chloroform:methanol 1:1 (v:v) or solvent A (see Note 13). If needed, centrifuge samples at $2000 \mathrm{rpm}$ for $5 \mathrm{~min}$ to remove potential insoluble residues before injection.

4. If semi-quantitative comparative analysis is the goal, determine the quantity of lipid extract to be injected for a linear response of the different lipid families to be screened and compared (see Note 16):

- Inject a range from 0 to $20 \mu \mathrm{g}$ of reference lipid extract.

- Extract ion chromatograms for each lipid of interest and integrate area under the chromatograms.

- Plot the curve of chromatogram area versus injected quantity of sample for the different lipid families of interest.

- Determine the injection quantity range over which the majority of lipids show a linear response.

\subsection{Targeted screening and comparative analysis}

\section{- $\quad$ Semi-automated screening of mycobacterial lipid families}

Once the map of detected lipids is established routine screening of these families can be undertaken. For a moderate number of analyses, one of the easiest ways is to use the data acquisition and visualisation software associated to the spectrometer and to extract the ion chromatograms at the expected $\mathrm{m} / \mathrm{z}$ for representative or all acylforms of the lipid families (see Note 14), with a tolerance within the mass spectrometer mass accuracy (1$10 \mathrm{ppm}$ ). It is often possible to pre-register a list of $\mathrm{m} / \mathrm{z}$ for the simultaneous extraction of the ion chromatograms of all the lipids of interest.

\section{- $\quad$ Automated lipid annotation}

For a large number of samples such as biological fluids from patient cohorts or a mycobacteria library, it can be envisaged to set up a bioinformatic workflow for the extraction of all the chromatograms of the generated datasets using an appropriate peak picking algorithm and/or to carry out an automatic annotation with software integrating the available databases, MycoMass [12] or Mtb LipidDB [30] (see Table 2 and Note 17), such as the MS-LAMP software [33].

Several lipidomic data processing software packages have been developed for filtering, peak picking, peak integration and alignment, such as the online XCMS platform (https://xcmsonline.scripps.edu) [34], MZmine 2 [35] or MS-DIAL [36]. Each require converting the raw MS files in 
mzXML format, which can be performed either with the data export module of the mass spectrometer data acquisition software (such as Agilent MassHunter) or can be carried out using msConvert ProteoWizard [37,38]. Processed data can then be exported toward data annotation software.

- $\quad$ Semi-quantitative comparison of mycobacterial lipid families present in studied samples

The area under the extracted-ion chromatogram of a given lipid species correlates with its abundance. However, translating this area in absolute quantity requires performing dose response curves using standards, which is still challenging for mycobacterial lipids due to the poor availability of standards. As well, differences in chromatograms areas between lipid classes cannot be translated into differences in absolute quantity without determining the response factor of each lipid class. Nonetheless, changes in the area under the chromatogram for a given lipid across samples of the same nature reflects changes in absolute quantity. Hence, the comparison of the lipid profiles obtained for different samples of the same nature allows highlighting changes in the relative proportion of the different lipid families without knowing their absolute value.

Normalization of the experiment is crucial to perform such semi-quantitative comparative analysis. Since the use of detergent in mycobacteria culture is not recommended, strong bacterial aggregation is observed and optical density of the cultures cannot be used for the normalisation of the comparative analysis of different mycobacterial strains (see Notes 4). Instead, comparative analysis can be normalized based on the weight of extracted bacteria pellet or on the amount of injected lipid extract (assuming that the same amount of lipids are extracted per bacillus for different strains) (see Note 8).

These considerations being said, the comparative analyses of samples should be performed as follows:

1- Add an internal standard(s) (see Note 5) to studied samples before lipid extraction to control the quality of the extraction process and normalisation.

2- Perform HPLC-MS analysis as above described by injecting the amount of lipid extract according to the chosen normalisation method (see Notes 8 and 18) and to the previously determined range of linear response of the studied lipid families (see Note 16). 
3- Extract for each dataset the ion chromatograms at the expected $\mathrm{m} / \mathrm{z}$ for representative or all acylforms of the lipid families (see Note 14), with a mass tolerance within the mass spectrometer mass accuracy (1-10 ppm), and integrate signals under the chromatogram curves.

\section{Notes}

1. Handle all organic solvents under the hood. Chloroform can be replaced by dichloromethane, which is less carcinogenic.

2. This approach was initially developed using an Agilent Technologies 6520 Accurate-Mass Q-Tof and a 1200 series HPLC system with a Varian MonoChrom Diol (dihydroxypropyl group bonded phase) column (150 mm $\times 2 \mathrm{~mm}, 3 \mu \mathrm{m}$ particles of $10 \AA$ porosity) and a Varian MonoChrom Diol guard column $(3 \mu \mathrm{m} \times 4.6 \mathrm{~mm})$. Elution profile obtained with the Varian Diol column is presented in Table 1 . This column is discontinued but equivalent Diol columns with the same characteristics are available (for example, Agilent or Princeton diol columns). Using equivalent Diol columns leads to similar order of elution of $M$. tuberculosis lipids families but with possible moderate variation in retention time. 3. Mass spectrometers show variable performance (sensitivity and dynamic range) and M. tuberculosis lipid families have different ionization properties. Hence, applying this approach to a different mass spectrometer might require the optimization of the ionization parameters of the instrument in order to allow the detection of the different lipid families. For information, this approach has been later successfully transferred on LTQ Orbitrap XL Hybrid Ion Trap-Orbitrap Mass Spectrometer (Thermo) mass spectrometer coupled to a Dionex Ultimate 3000 HPLC system and to a Xevo G2 Qtof (WATERS) mass spectrometers (unpublished).

4. Traces of detergents alter lipidomic analyses by inducing important contaminant mass spectrometry signals and by suppressing the signal of relevant lipids. It is therefore necessary to take several precautions with regard to the culture media, the quality of the solvents and the appropriate use of plastic and glass materials.

Culture conditions: Mycobacteria are usually grown in standard Middlebrook 7H9 (Difco) or Sauton medium. It is recommended to avoid the use of detergent such as Tween, which is routinely employed to reduce the characteristic aggregation of mycobacteria in liquid media. Indeed, detergents 
stick to the bacillus envelope and are recovered during lipid extraction by organic solvents. When growth monitoring by optical density measurement is required, it is preferable to use tyloxapol. Another alternative is to prepare a replicate culture in the presence of detergent in parallel with detergent-free cultures for each strain, in order to estimate their growth phase based on optical density.

Material: Material is also a source of contaminations. Methanol is compatible with plastic consumables but as soon as chloroform- or dichloromethane is used any contact with plastic consumables (pipette, tubes and caps) is strictly forbidden and therefore glass material must be used (pipette, syringe and tubes with PTFE caps). In addition, glassware washed with soap such as in common laboratory laundry is still a source of contaminations. Hence, attention has to be paid to clean the glassware twice with 1:1 chloroform:methanol before use. Polytetrafluoroethylene (PTFE) caps must be used with screw glass tubes.

Solvents: All solvents should be HPLC-grade and freshly prepared.

5. Addition of a known quantity of non-mycobacterial lipid standard, such as phosphatidylcholine for example, to the bacteria pellet allows controlling the overall lipid extraction process and to normalize comparative analyses. The intensity of the MS signal of the chosen standard should be within the intensity range of the analytes of interest. The determination of the response factor of the standard in the used LC-MS set up will determine the suitable amount of standard to be added.

6. The tip of the plastic pipette must not contact the chloroform:methanol solution when transferring the methanolic bacteria solution. All following steps of extraction protocol must be performed in a chemical hood

7. When manipulating live virulent M. tuberculosis strains, step 1-7 are performed in BSL3 facility. Contacting the bacterial pellet with chloroform:methanol mixture also aims at killing the bacteria before pursuing the protocol outside of the BSL3 facility. Successful sterilization relies on the ratio wet pellet / chloroform:methanol. From $50 \mathrm{~mL}$ of mycobacterium culture, recovered wet pellet is typically $\leq 1 \mathrm{~mL}$. A ratio of 4 parts solvent to 1 part wet pellet $(\mathrm{v} / \mathrm{v})$ is expected to sterilize the sample overnight. In any case, when setting up this protocol, the sterilization conditions must be validated by a controlled experiment showing the absence of colony forming unit when plating the so-called "sterile" pellet on Petri dish. Once the sample is sterilized, spray the outside of the glass container with tuberculocidal agent and continue the protocol outside of the BSL3 facility in a chemical hood using glass pipettes or syringes and rinsed glassware as described in Note 4. 
8. About 1-1.5 mg of dried lipids is usually recovered from $50 \mathrm{~mL}$ of $\log$ phase culture. If normalization of experiments is later carried out on the quantity of injected lipid extract, weight measurement must be as reliable as possible, which requires the complete evaporation of the solvents. Repeat weighing of the dried lipid film on a microbalance 20 min later and ensure a constant weight is reached otherwise desiccation time must be prolonged. Drying under vacuum might be necessary depending on the amount of lipid extract.

9. Best results are obtained with freshly prepared extracts. Lipid extracts should not be stored in a dry state. Oxidative degradation is slower in solutions (up to 1 year). Dichloromethane is more stable than chloroform for long-term storage, which should take place in a flammable storage laboratory freezer. Air and light should be avoided. To minimise the cleavage of ester lipids during long periods of storage, methanol can be replaced by 2-propanol in the solvent mixture.

10. HPLC solvents A and B should be freshly prepared and should not be stored. If (light) precipitates are observed when adding the additives to the solvent mixtures, 1 minute in a sonic bath can help the solubilisation. The HPLC system should be equipped with solvent resistant gaskets and solvent bottles with integrated air valve to avoid solvent evaporation. Sufficient volume of solvents should be prepared in order to analyse all the samples to be compared with the same batch of solvents and to avoid retention time variation.

11. For future screening of mycobacterial lipids in different samples or for different mycobacteria strains it is necessary to first establish a detection $\operatorname{map}(\mathrm{m} / \mathrm{z}$, retention time) of these different families for a given HPLC-MS system. Mass spectrometers show variable performance (sensitivity and dynamic range) and M. tuberculosis glycolipid families have different ionization properties. Hence, applying this approach with a given mass spectrometer might require the optimization of the ionization parameters of the instrument in order to allow the detection of all lipid families. For information, initially set up using an Agilent 6520 (ESI)-Q-tof mass spectrometer, this approach has been later successfully transferred on a Thermo LTQ Orbitrap XL and a Waters Xevo G2 Qtof mass spectrometers (unpublished). Using the Agilent Technologies 6520 AccurateMass Q-Tof in full scan mode, recommended Dual ESI source and acquisition parameters are the following, as previously published [1]: gas temperature $325^{\circ} \mathrm{C}, 5 \mathrm{~L} / \mathrm{min}$ drying gas flow, $30 \mathrm{psig}$ nebulizer pressure, VCap 5,500 V. Spectra are collected from $\mathrm{m} / \mathrm{z} 100$ to 3,000 at $1 \mathrm{spectrum} / \mathrm{s}$ with continuous infusion of calibrants (m/z 121.050873 and 922.009798 in positive ion mode, m/z 112.985587 and 1033.98810 in negative ion mode). 
12. Standards of mycobacterial lipids are currently poorly marketed. Polar Aventi mycolic acids are distributed by Sigma Aldrich and “ Mycobacterium tuberculosis, Strain H37Rv, Total Lipids" (NR-14837) is provided by the BEI resources. Alternatives for MS signal optimisation are to directly work with the total lipid extract from M. tuberculosis culture to reproduce the lipid profile detailed in Table 1 or to contact laboratories with expertise in M. tuberculosis lipids purification or organic synthesis to obtain pure lipids for the optimization of individual lipid families detection.

13. The amount of lipids to be injected depends on the instrument sensibility. Agilent Technologies 6520 Accurate-Mass Q-Tof requires about 10 micrograms of M. tuberculosis total lipid extract to detect the different lipid families listed in Table 1 . The same instrument shows a limit of detection of $10^{-12}$ to $10^{-9}$ mole injected when analysing purified lipid standards [1].

14. Each M. tuberculosis lipid family is composed of not one, but more often of several dozen acylforms that share a common polar head. Hence, the signal corresponding to a given lipid family is characterized by a series of molecular ions detected with $\mathrm{m} / \mathrm{z}$ values that differ by 14.0156 a.m.u ( $\mathrm{CH}_{2}$ group), which elute within a narrow retention time window on diol chromatography. When performing the semi-quantitative comparison of the lipid profile of different samples, it is possible to perform the comparison using one representative acylform by lipid family, if the acylform profile of the lipid families is conserved between samples.

15. While MS/MS databases are not available for M. tuberculosis lipids, fragmentation profiles of several M. tuberculosis lipids families have been previously published [1].

16. When the goal is the semi-quantitative comparison of the lipid profiles of different strains (for example, WT, mutant and complemented strains) or of a same strain grown in different conditions, it is important to ensure that the injected quantity of lipid extract is within the linear response range of the lipids of interest. Indeed, the area under the chromatogram of a given molecular lipid species increases proportionally with its abundance until the signal saturates or even gradually extinguishes. Because each lipid family has its own response factor under given mass spectrometry settings, it is therefore important that the concentration of the studied lipid extract (i.e. the injected quantity) is suitable to assess changes in abundance for as many, if not all, lipid families as possible. 
17. These databases represent a unique resource of information but it is important to keep in mind that they consist of lists of theoretical calculated $\mathrm{m} / \mathrm{z}$ for the acylforms of the different mycobacterial lipid families described in the literature. The MycoMass was built to provide a tool to assist MS signals assignments or at least to propose possible formulas. As culture/infection conditions modulate the acylform profile of lipids, the list of listed acylforms is not limited to the published data but is sometimes extended in terms of acyl chain length and combination of fatty acids

(Table 2). In addition, these databases do not contain retention time criteria, which are method- and therefore laboratory-dependent. Hence, a match between a detected $\mathrm{m} / \mathrm{z}$ and an entry in these databases does not constitute, by itself, a definitive assignment. The use of these databases for the annotation of large HPLC-MS datasets currently requires an extensive manual curating to remove annotations that are incoherent with observed RTs. When using these databases on datasets generated using a different chromatographic separation, annotations of MS signals must be confirmed by MS/MS experiments. The time saved using database for the annotation of large MS datasets is to the user's appreciation.

18. When comparing the lipid profile of different strains, it is desirable to ensure that the cultures are in the same growth phase (log versus late phase). One replicate culture in the presence of detergent can be carried out in parallel with detergent-free cultures for each strain, in order to estimate their growth phase based on optical density measurement.

\section{References}

1. Jurowski K, Kochan K, Walczak J, Baranska M, Piekoszewski W, Buszewski B (2017) Analytical Techniques in Lipidomics: State of the Art. Critical reviews in analytical chemistry 47 (5):418-437. doi:10.1080/10408347.2017.1310613

2. Zullig T, Trotzmuller M, Kofeler HC (2020) Lipidomics from sample preparation to data analysis: a primer. Analytical and bioanalytical chemistry 412 (10):21912209. doi:10.1007/s00216-019-02241-y

3. Minnikin DE, Brennan PJ (2020) Lipids of Clinically Significant Mycobacteria. In: H. G (ed) Health Consequences of Microbial Interactions with Hydrocarbons, Oils, and Lipids. Handbook of Hydrocarbon and Lipid Microbiology. Springer, Cham, pp 1-76. doi:https://doi.org/10.1007/978-3-319-72473-7_7-1

4. Becker K, Sander P (2016) Mycobacterium tuberculosis lipoproteins in virulence and immunity- fighting with a double-edged sword. FEBS letters 590 (21):38003819. doi:10.1002/1873-3468.12273

5. Neyrolles O, Guilhot C (2011) Recent advances in deciphering the contribution of Mycobacterium tuberculosis lipids to pathogenesis. Tuberculosis 91 (3):187195. doi:10.1016/j.tube.2011.01.002

6. Ray A, Cot M, Puzo G, Gilleron M, Nigou J (2013) Bacterial cell wall macroamphiphiles: pathogen-/microbe-associated molecular patterns detected by mammalian innate immune system. Biochimie 95 (1):33-42. doi:10.1016/j.biochi.2012.06.007 
7. Chiaradia L, Lefebvre C, Parra J, Marcoux J, Burlet-Schiltz O, Etienne G, Tropis M, Daffe M (2017) Dissecting the mycobacterial cell envelope and defining the composition of the native mycomembrane. Scientific reports 7 (1):12807. doi:10.1038/s41598-017-12718-4

8. Hoffmann C, Leis A, Niederweis M, Plitzko JM, Engelhardt H (2008) Disclosure of the mycobacterial outer membrane: cryo-electron tomography and vitreous sections reveal the lipid bilayer structure. Proceedings of the National Academy of Sciences of the United States of America 105 (10):3963-3967. doi:10.1073/pnas.0709530105

9. Zuber B, Chami M, Houssin C, Dubochet J, Griffiths G, Daffe M (2008) Direct visualization of the outer membrane of mycobacteria and corynebacteria in their native state. Journal of bacteriology 190 (16):5672-5680. doi:10.1128/JB.01919-07

10. Bansal-Mutalik R, Nikaido $\mathrm{H}$ (2014) Mycobacterial outer membrane is a lipid bilayer and the inner membrane is unusually rich in diacyl phosphatidylinositol dimannosides. Proceedings of the National Academy of Sciences of the United States of America 111 (13):4958-4963. doi:10.1073/pnas.1403078111

11. Sani M, Houben EN, Geurtsen J, Pierson J, de Punder K, van Zon M, Wever B, Piersma SR, Jimenez CR, Daffe M, Appelmelk BJ, Bitter W, van der Wel N, Peters

PJ (2010) Direct visualization by cryo-EM of the mycobacterial capsular layer: a labile structure containing ESX-1-secreted proteins. PLoS pathogens 6 (3):e1000794. doi:10.1371/journal.ppat.1000794

12. Layre E, Sweet L, Hong S, Madigan CA, Desjardins D, Young DC, Cheng TY, Annand JW, Kim K, Shamputa IC, McConnell MJ, Debono CA, Behar SM, Minnaard AJ, Murray M, Barry CE, 3rd, Matsunaga I, Moody DB (2011) A comparative lipidomics platform for chemotaxonomic analysis of Mycobacterium tuberculosis. Chemistry \& biology 18 (12):1537-1549. doi:10.1016/j.chembiol.2011.10.013

13. Becker K, Haldimann K, Selchow P, Reinau LM, Dal Molin M, Sander P (2017) Lipoprotein Glycosylation by Protein-O-Mannosyltransferase (MAB_1122c) Contributes to Low Cell Envelope Permeability and Antibiotic Resistance of Mycobacterium abscessus. Frontiers in microbiology 8:2123. doi:10.3389/fmicb.2017.02123

14. Laneelle MA, Nigou J, Daffe M (2015) Lipid and lipoarabinomannan isolation and characterization. Methods in molecular biology 1285:77-103. doi:10.1007/978-1-4939-2450-9_5

15. Parra J, Marcoux J, Poncin I, Canaan S, Herrmann JL, Nigou J, Burlet-Schiltz O, Riviere M (2017) Scrutiny of Mycobacterium tuberculosis 19 kDa antigen proteoforms provides new insights in the lipoglycoprotein biogenesis paradigm. Scientific reports 7:43682. doi:10.1038/srep43682

16. Nigou J, Gilleron M, Brando T, Puzo G (2004) Structural analysis of mycobacterial lipoglycans. Applied biochemistry and biotechnology 118 (1-3):253-267. doi:10.1385/abab:118:1-3:253

17. Slayden RA, Barry CE, 3rd (2001) Analysis of the Lipids of Mycobacterium tuberculosis. Methods in molecular medicine 54:229-245. doi:10.1385/1-59259147-7:229

18. Lanéelle M, Nigou J, Daffé M (2005) Lipid and Lipoarabinomannan Isolation and Characterization. In: T. P, D. R (eds) Mycobacteria Protocols, vol 1285. Humana Press, New York, NY. doi:https://doi.org/10.1007/978-1-4939-2450-9_5

19. Portevin D, Sukumar S, Coscolla M, Shui G, Li B, Guan XL, Bendt AK, Young D, Gagneux S, Wenk MR (2014) Lipidomics and genomics of Mycobacterium tuberculosis reveal lineage-specific trends in mycolic acid biosynthesis. MicrobiologyOpen 3 (6):823-835. doi:10.1002/mbo3.193

20. Shui G, Bendt AK, Jappar IA, Lim HM, Laneelle M, Herve M, Via LE, Chua GH, Bratschi MW, Zainul Rahim SZ, Michelle AL, Hwang SH, Lee JS, Eum SY, Kwak HK, Daffe M, Dartois V, Michel G, Barry CE, 3rd, Wenk MR (2012) Mycolic acids as diagnostic markers for tuberculosis case detection in humans and drug efficacy in mice. EMBO molecular medicine 4 (1):27-37. doi:10.1002/emmm.201100185 
21. Layre E, Paepe DC, Larrouy-Maumus G, Vaubourgeix J, Mundayoor S, Lindner B, Puzo G, Gilleron M (2011) Deciphering sulfoglycolipids of Mycobacterium tuberculosis. Journal of lipid research 52 (6):1098-1110. doi:10.1194/jlr.M013482

22. Jain M, Petzold CJ, Schelle MW, Leavell MD, Mougous JD, Bertozzi CR, Leary JA, Cox JS (2007) Lipidomics reveals control of Mycobacterium tuberculosis virulence lipids via metabolic coupling. Proceedings of the National Academy of Sciences of the United States of America 104 (12):5133-5138. doi:10.1073/pnas.0610634104

23. Larrouy-Maumus G, Puzo G (2015) Mycobacterial envelope lipids fingerprint from direct MALDI-TOF MS analysis of intact bacilli. Tuberculosis 95 (1):75-85. doi:10.1016/j.tube.2014.11.001

24. Gilleron M, Lindner B, Puzo G (2006) MS/MS approach for characterization of the fatty acid distribution on mycobacterial phosphatidyl-myo-inositol mannosides. Analytical chemistry 78 (24):8543-8548. doi:10.1021/ac061574a

25. Hsu FF, Turk J, Owens RM, Rhoades ER, Russell DG (2007) Structural characterization of phosphatidyl-myo-inositol mannosides from Mycobacterium bovis Bacillus Calmette Guerin by multiple-stage quadrupole ion-trap mass spectrometry with electrospray ionization. I. PIMs and lyso-PIMs. Journal of the American Society for Mass Spectrometry 18 (3):466-478. doi:10.1016/j.jasms.2006.10.012

26. Hsu FF, Turk J, Owens RM, Rhoades ER, Russell DG (2007) Structural characterization of phosphatidyl-myo-inositol mannosides from Mycobacterium bovis Bacillus Calmette Guerin by multiple-stage quadrupole ion-trap mass spectrometry with electrospray ionization. II. Monoacyl- and diacyl-PIMs. Journal of the American Society for Mass Spectrometry 18 (3):479-492. doi:10.1016/j.jasms.2006.10.020

27. Fujita Y, Naka T, Doi T, Yano I (2005) Direct molecular mass determination of trehalose monomycolate from 11 species of mycobacteria by MALDI-TOF mass spectrometry. Microbiology 151 (Pt 5):1443-1452. doi:10.1099/mic.0.27791-0

28. Fujita Y, Naka T, McNeil MR, Yano I (2005) Intact molecular characterization of cord factor (trehalose 6,6'-dimycolate) from nine species of mycobacteria by MALDI-TOF mass spectrometry. Microbiology 151 (Pt 10):3403-3416. doi:10.1099/mic.0.28158-0

29. Madigan CA, Cheng TY, Layre E, Young DC, McConnell MJ, Debono CA, Murry JP, Wei JR, Barry CE, 3rd, Rodriguez GM, Matsunaga I, Rubin EJ, Moody DB (2012) Lipidomic discovery of deoxysiderophores reveals a revised mycobactin biosynthesis pathway in Mycobacterium tuberculosis. Proceedings of the National Academy of Sciences of the United States of America 109 (4):1257-1262. doi:10.1073/pnas.1109958109

30. Sartain MJ, Dick DL, Rithner CD, Crick DC, Belisle JT (2011) Lipidomic analyses of Mycobacterium tuberculosis based on accurate mass measurements and the novel "Mtb LipidDB". Journal of lipid research 52 (5):861-872. doi:10.1194/jlr.M010363

31. Galagan JE, Minch K, Peterson M, Lyubetskaya A, Azizi E, Sweet L, Gomes A, Rustad T, Dolganov G, Glotova I, Abeel T, Mahwinney C, Kennedy AD, Allard R, Brabant W, Krueger A, Jaini S, Honda B, Yu WH, Hickey MJ, Zucker J, Garay C, Weiner B, Sisk P, Stolte C, Winkler JK, Van de Peer Y, lazzetti P, Camacho D, Dreyfuss J, Liu Y, Dorhoi A, Mollenkopf HJ, Drogaris P, Lamontagne J, Zhou Y, Piquenot J, Park ST, Raman S, Kaufmann SH, Mohney RP, Chelsky D, Moody DB, Sherman DR, Schoolnik GK (2013) The Mycobacterium tuberculosis regulatory network and hypoxia. Nature 499 (7457):178-183. doi:10.1038/nature12337

32. Layre E, Lee HJ, Young DC, Martinot AJ, Buter J, Minnaard AJ, Annand JW, Fortune SM, Snider BB, Matsunaga I, Rubin EJ, Alber T, Moody DB (2014) Molecular profiling of Mycobacterium tuberculosis identifies tuberculosinyl nucleoside products of the virulence-associated enzyme Rv3378c. Proceedings of the National Academy of Sciences of the United States of America 111 (8):2978-2983. doi:10.1073/pnas.1315883111 


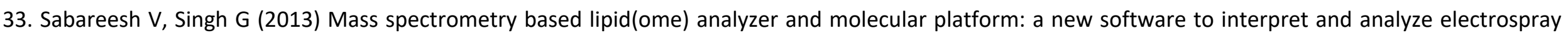

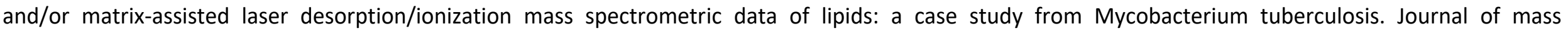
spectrometry : JMS 48 (4):465-477. doi:10.1002/jms.3163

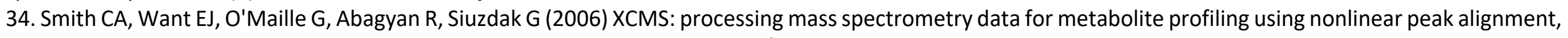
matching, and identification. Analytical chemistry 78 (3):779-787. doi:10.1021/ac051437y

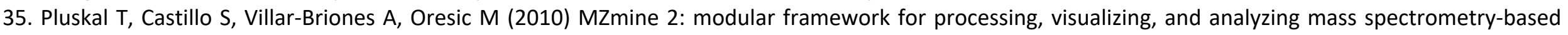
molecular profile data. BMC bioinformatics 11:395. doi:10.1186/1471-2105-11-395

36. Tsugawa H, Cajka T, Kind T, Ma Y, Higgins B, Ikeda K, Kanazawa M, VanderGheynst J, Fiehn O, Arita M (2015) MS-DIAL: data-independent MS/MS deconvolution for comprehensive metabolome analysis. Nature methods 12 (6):523-526. doi:10.1038/nmeth.3393

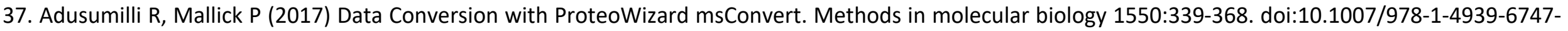
$6 \_23$

38. Kessner D, Chambers M, Burke R, Agus D, Mallick P (2008) ProteoWizard: open source software for rapid proteomics tools development. Bioinformatics 24 (21):2534-2536. doi:10.1093/bioinformatics/btn323 


\section{Figure/Table Legends}

Figure 1: Examples of unique lipids extracted by organic solvents from the mycobacterial envelope. Exposure of mycobacteria with organic solvents allows recovering the "extractable lipids" that compose the plasma membrane and the mycomembrane. AG: arabinogalactan, LAM: lipoarabinomannan, LM: lipomannan, LP: lipoprotein, MA: mycolic acids.

Table 1: List of detected mycobacterial lipid families and acylforms. Are listed the formula of the molecular ions of each acylform, the detected $\mathrm{m} / \mathrm{z}$ of the indicated adduct, and their indicative retention times (subjected to changes depending on the Diol column brand). Detected $\mathrm{m} / \mathrm{z}$ are listed for only one ion-mode. In positive ion-mode all lipid families are detected and $[\mathrm{M}+\mathrm{NH} 4]^{+}$and $[\mathrm{M}+\mathrm{H}]^{+}$adducts are the most commonly detected adducts. In negative ion mode, detected lipids are those that are naturally negatively charged $[\mathrm{M}-\mathrm{H}]^{-}$such as the phosphated and sulphated lipids (phospholipids, PIM and sulfoglycolipids) while neutral glycolipids are either not detected or detected as $\left[\mathrm{M}^{+} \mathrm{HCOO}^{-}\right]^{-}$adducts depending on the MS instrument. Coverage of the repertoire of M. tuberculosis lipids will depend on the mass spectrometer's performances. It is to note that TDM is absent of the list. TDM produced by Mycobacterium species is a family of very large ( $\mathrm{m} / \mathrm{z}$ centered $\sim 2700$ a.m.u) and hydrophobic acylforms, which are poorly ionising by electrospray. Therefore, TDM cannot be listed as routinely detected by HPLC-MS. TLC and MALDI-Tof are currently the most successful methods for TDM detection [28].

Table 2: Excerpt of the MycoMass database illustrating the provided data and their organisation, which follows the LIPIDMAPS classification. 
Table 1

\begin{tabular}{|c|c|c|c|c|}
\hline Lipid family & Formula & $\begin{array}{c}\text { lon- } \\
\text { mode/Adduct }\end{array}$ & $\begin{array}{l}\text { Calculated } \\
\mathrm{m} / \mathrm{z}\end{array}$ & $\begin{array}{l}\text { Indicative } \\
\text { RT (min) }\end{array}$ \\
\hline \multirow{16}{*}{$\begin{array}{c}\text { phthiocerol dimycocerosate } \\
\text { PDIM A/A' }\end{array}$} & C87H172O5 & pos/[M+NH4]+ & 1315.3543 & \multirow{32}{*}{3.6} \\
\hline & $\mathrm{C} 88 \mathrm{H} 174 \mathrm{O} 5$ & pos/[M+NH4]+ & 1329.3699 & \\
\hline & $\mathrm{C} 89 \mathrm{H} 176 \mathrm{O} 5$ & pos/[M+NH4]+ & 1343.3856 & \\
\hline & $\mathrm{C} 90 \mathrm{H} 178 \mathrm{O} 5$ & pos/[M+NH4]+ & 1357.4012 & \\
\hline & C91H180O5 & pos/[M+NH4]+ & 1371.4169 & \\
\hline & $\mathrm{C} 92 \mathrm{H} 182 \mathrm{O} 5$ & pos/[M+NH4]+ & 1385.4325 & \\
\hline & C93H184O5 & pos/[M+NH4]+ & 1399.4482 & \\
\hline & C94H186O5 & pos/[M+NH4]+ & 1413.4638 & \\
\hline & C95H188O5 & pos/[M+NH4]+ & 1427.4795 & \\
\hline & $\mathrm{C} 96 \mathrm{H} 190 \mathrm{O} 5$ & pos/[M+NH4]+ & 1441.4951 & \\
\hline & C97H192O5 & pos/[M+NH4]+ & 1455.5108 & \\
\hline & C98H194O5 & pos/[M+NH4]+ & 1469.5264 & \\
\hline & $\mathrm{C99H} 196 \mathrm{O} 5$ & pos/[M+NH4]+ & 1483.5421 & \\
\hline & C100H198O5 & pos/[M+NH4]+ & 1497.5577 & \\
\hline & C101H200O5 & pos/[M+NH4]+ & 1511.5734 & \\
\hline & $\mathrm{C} 102 \mathrm{H} 202 \mathrm{O} 5$ & pos/[M+NH4]+ & 1525.5891 & \\
\hline \multirow{16}{*}{$\begin{array}{l}\text { phthiocerol dimycocerosate } \\
\text { PDIM B }\end{array}$} & C87H170O5 & pos/[M+NH4]+ & 1313.3387 & \\
\hline & C88H172O5 & pos/[M+NH4]+ & 1327.3543 & \\
\hline & C89H174O5 & pos/[M+NH4]+ & 1341.3700 & \\
\hline & $\mathrm{C} 90 \mathrm{H} 176 \mathrm{O} 5$ & pos/[M+NH4]+ & 1355.3856 & \\
\hline & C91H178O5 & pos/[M+NH4]+ & 1369.4013 & \\
\hline & $\mathrm{C} 92 \mathrm{H} 180 \mathrm{O} 5$ & pos/[M+NH4]+ & 1383.4169 & \\
\hline & C93H182O5 & pos/[M+NH4]+ & 1397.4326 & \\
\hline & $\mathrm{C} 94 \mathrm{H} 184 \mathrm{O} 5$ & pos/[M+NH4]+ & 1411.4482 & \\
\hline & C95H186O5 & pos/[M+NH4]+ & 1425.4639 & \\
\hline & C96H188O5 & pos/[M+NH4]+ & 1439.4795 & \\
\hline & C97H19005 & pos/[M+NH4]+ & 1453.4952 & \\
\hline & $\mathrm{C} 98 \mathrm{H} 192 \mathrm{O} 5$ & pos/[M+NH4]+ & 1467.5108 & \\
\hline & С99H194O5 & pos/[M+NH4]+ & 1481.5265 & \\
\hline & C100H196O5 & pos/[M+NH4]+ & 1495.5421 & \\
\hline & C101H198O5 & pos/[M+NH4]+ & 1509.5578 & \\
\hline & $\mathrm{C} 102 \mathrm{H} 20005$ & pos/[M+NH4]+ & 1523.5734 & \\
\hline
\end{tabular}


Table 1

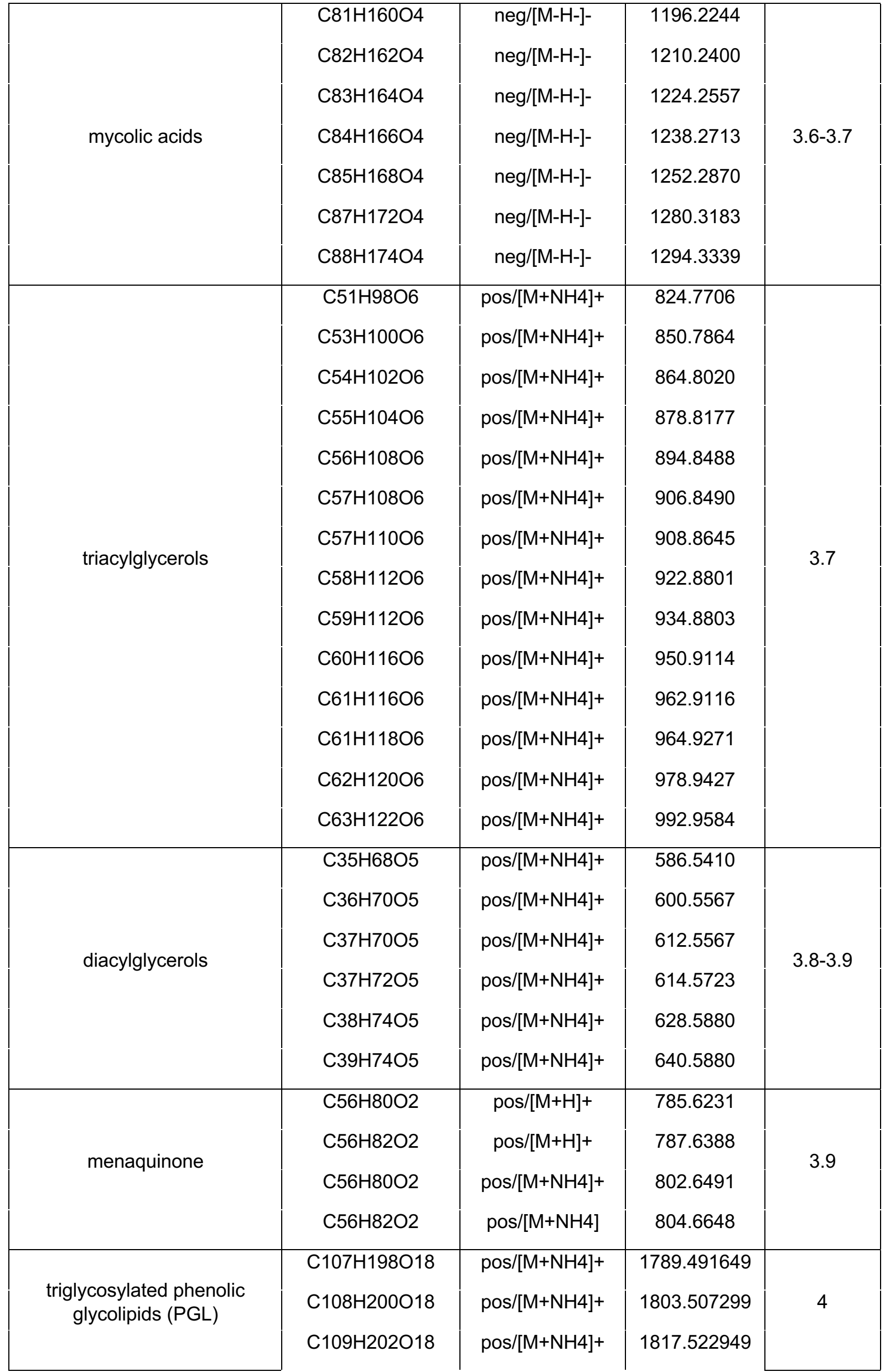


Table 1

\begin{tabular}{|c|c|c|c|c|}
\hline & $\begin{array}{l}\mathrm{C} 110 \mathrm{H} 204 \mathrm{O} 18 \\
\mathrm{C} 111 \mathrm{H} 206 \mathrm{O} 18 \\
\mathrm{C} 112 \mathrm{H} 208 \mathrm{O} 18 \\
\mathrm{C} 113 \mathrm{H} 210018 \\
\mathrm{C} 114 \mathrm{H} 212 \mathrm{O} 18 \\
\mathrm{C} 115 \mathrm{H} 214 \mathrm{O} 18 \\
\mathrm{C} 116 \mathrm{H} 216 \mathrm{O} 18 \\
\mathrm{C} 117 \mathrm{H} 218 \mathrm{O} 18 \\
\mathrm{C} 118 \mathrm{H} 220018 \\
\mathrm{C} 119 \mathrm{H} 222 \mathrm{O} 18 \\
\mathrm{C} 120 \mathrm{H} 224 \mathrm{O} 18\end{array}$ & $\begin{array}{l}\text { pos/[M+NH4]+ } \\
\text { pos/[M+NH4]+ } \\
\text { pos/[M+NH4]+ } \\
\text { pos/[M+NH4]+ } \\
\text { pos/[M+NH4]+ } \\
\text { pos/[M+NH4]+ } \\
\text { pos/[M+NH4]+ } \\
\text { pos/[M+NH4]+ } \\
\text { pos/[M+NH4]+ } \\
\text { pos/[M+NH4]+ } \\
\text { pos/[M+NH4]+ }\end{array}$ & $\begin{array}{r}1831.538599 \\
1845.554249 \\
1859.569899 \\
1873.585549 \\
1887.601199 \\
1901.616849 \\
1915.632499 \\
1929.648149 \\
1943.663799 \\
1957.679449 \\
1971.695099\end{array}$ & \\
\hline $\begin{array}{l}\text { glucose monomycolate } \\
\text { alpha }\end{array}$ & $\begin{array}{l}\mathrm{C} 80 \mathrm{H} 154 \mathrm{O} 8 \\
\mathrm{C} 82 \mathrm{H} 158 \mathrm{O} 8 \\
\mathrm{C} 84 \mathrm{H} 162 \mathrm{O} 8 \\
\mathrm{C} 86 \mathrm{H} 166 \mathrm{O} 8\end{array}$ & $\begin{array}{l}\text { pos/[M+NH4]+ } \\
\text { pos/[M+NH4]+ } \\
\text { pos/[M+NH4]+ } \\
\text { pos/[M+NH4]+ }\end{array}$ & $\begin{array}{r}1261.1982 \\
1289.2295 \\
1317.2608 \\
1345.2921\end{array}$ & \\
\hline $\begin{array}{l}\text { glucose monomycolate } \\
\text { keto }\end{array}$ & $\begin{array}{l}\mathrm{C} 80 \mathrm{H} 154 \mathrm{O} 9 \\
\mathrm{C} 81 \mathrm{H} 156 \mathrm{O} 9 \\
\mathrm{C} 83 \mathrm{H} 160 \mathrm{9} 9 \\
\mathrm{C} 85 \mathrm{H} 164 \mathrm{O} 9 \\
\mathrm{C} 87 \mathrm{H} 168 \mathrm{O} 9 \\
\mathrm{C} 88 \mathrm{H} 170 \mathrm{O} 9 \\
\mathrm{C} 92 \mathrm{H} 178 \mathrm{O} 9 \\
\mathrm{C} 87 \mathrm{H} 170 \mathrm{O} 9 \\
\mathrm{C} 89 \mathrm{H} 174 \mathrm{O} 9 \\
\mathrm{C} 91 \mathrm{H} 178 \mathrm{O} 9 \\
\mathrm{C} 93 \mathrm{H} 182 \mathrm{O} 9 \\
\mathrm{C} 95 \mathrm{H} 186 \mathrm{O} 9\end{array}$ & $\begin{array}{l}\text { pos/[M+NH4]+ } \\
\text { pos/[M+NH4]+ } \\
\text { pos/[M+NH4]+ } \\
\text { pos/[M+NH4]+ } \\
\text { pos/[M+NH4]+ } \\
\text { pos/[M+NH4]+ } \\
\text { pos/[M+NH4]+ } \\
\text { pos/[M+NH4]+ } \\
\text { pos/[M+NH4]+ } \\
\text { pos/[M+NH4]+ } \\
\text { pos/[M+NH4]+ } \\
\text { pos/[M+NH4]+ }\end{array}$ & $\begin{array}{l}1277.1931 \\
1291.2088 \\
1319.2401 \\
1347.2714 \\
1375.3027 \\
1389.3183 \\
1445.3809 \\
1377.3183 \\
1405.3496 \\
1433.3809 \\
1461.4122 \\
1489.4435\end{array}$ & 4.2 \\
\hline $\begin{array}{l}\text { trehalose monomycolate } \\
\text { alpha }\end{array}$ & $\begin{array}{l}\mathrm{C} 88 \mathrm{H} 168 \mathrm{O} 13 \\
\mathrm{C} 89 \mathrm{H} 170013 \\
\mathrm{C} 90 \mathrm{H} 172 \mathrm{O} 13 \\
\mathrm{C} 91 \mathrm{H} 174 \mathrm{O} 13 \\
\mathrm{C} 92 \mathrm{H} 176 \mathrm{O} 13 \\
\mathrm{C} 94 \mathrm{H} 180 \mathrm{O} 13 \\
\mathrm{C} 96 \mathrm{H} 184013\end{array}$ & $\begin{array}{l}\text { pos/[M+NH4]+ } \\
\text { pos/[M+NH4]+ } \\
\text { pos/[M+NH4]+ } \\
\text { pos/[M+NH4]+ } \\
\text { pos/[M+NH4]+ } \\
\text { pos/[M+NH4]+ } \\
\text { pos/[M+NH4]+ }\end{array}$ & $\begin{array}{r}1451.2823 \\
1465.2980 \\
1479.3136 \\
1493.3293 \\
1507.3449 \\
1535.3398 \\
1563.3711\end{array}$ & $6.2-6.6$ \\
\hline
\end{tabular}


Table 1

\begin{tabular}{|c|c|c|c|c|}
\hline \multirow{10}{*}{ trehalose monomycolate keto } & $\mathrm{C} 86 \mathrm{H} 164 \mathrm{O} 14$ & pos/[M+NH4]+ & 1439.2459 & \\
\hline & $\mathrm{C} 88 \mathrm{H} 168 \mathrm{O} 14$ & pos/[M+NH4]+ & 1467.2772 & \\
\hline & $\mathrm{C} 89 \mathrm{H} 170 \mathrm{O} 14$ & pos/[M+NH4]+ & 1481.2929 & \\
\hline & $\mathrm{C} 90 \mathrm{H} 172 \mathrm{O} 14$ & pos/[M+NH4]+ & 1495.3085 & \\
\hline & $\mathrm{C} 91 \mathrm{H} 174 \mathrm{O} 14$ & pos/[M+NH4]+ & 1509.3242 & \\
\hline & $\mathrm{C} 92 \mathrm{H} 176 \mathrm{O} 14$ & pos/[M+NH4]+ & 1523.3398 & \\
\hline & $\mathrm{C} 93 \mathrm{H} 178 \mathrm{O} 14$ & pos/[M+NH4]+ & 1537.3555 & \\
\hline & $\mathrm{C} 97 \mathrm{H} 186 \mathrm{O} 14$ & pos/[M+NH4]+ & 1593.4181 & \\
\hline & $\mathrm{C} 99 \mathrm{H} 190014$ & $\operatorname{pos} /[\mathrm{M}+\mathrm{NH} 4]+$ & 1621.4494 & \\
\hline & $\mathrm{C} 100 \mathrm{H} 192 \mathrm{O} 14$ & pos/[M+NH4]+ & 1635.4650 & \\
\hline \multirow{11}{*}{$\begin{array}{l}\text { trehalose monomycolate } \\
\text { methoxy }\end{array}$} & $\mathrm{C} 89 \mathrm{H} 172 \mathrm{O} 14$ & pos/[M+NH4]+ & 1483.3085 & \\
\hline & $\mathrm{C} 91 \mathrm{H} 176 \mathrm{O} 14$ & pos/[M+NH4]+ & 1511.3398 & \\
\hline & $\mathrm{C} 93 \mathrm{H} 180 \mathrm{O} 14$ & pos/[M+NH4]+ & 1539.3711 & \\
\hline & $\mathrm{C} 95 \mathrm{H} 184 \mathrm{O} 14$ & pos/[M+NH4]+ & 1567.4024 & \\
\hline & C97H188O14 & pos/[M+NH4]+ & 1595.4337 & \\
\hline & $\mathrm{C} 98 \mathrm{H} 190 \mathrm{O} 14$ & pos/[M+NH4]+ & 1609.4494 & \\
\hline & $\mathrm{C} 99 \mathrm{H} 192 \mathrm{O} 14$ & pos/[M+NH4]+ & 1623.4650 & \\
\hline & $\mathrm{C} 100 \mathrm{H} 194 \mathrm{O} 14$ & pos/[M+NH4]+ & 1637.4807 & \\
\hline & $\mathrm{C} 101 \mathrm{H} 196 \mathrm{O} 14$ & pos/[M+NH4]+ & 1651.4963 & \\
\hline & $\mathrm{C} 102 \mathrm{H} 198 \mathrm{O} 14$ & pos/[M+NH4]+ & 1665.5120 & \\
\hline & $\mathrm{C} 103 \mathrm{H} 200 \mathrm{O} 14$ & pos/[M+NH4]+ & 1679.5276 & \\
\hline \multirow{5}{*}{ diacyltrehalose } & $\mathrm{C} 52 \mathrm{H} 98 \mathrm{O} 13$ & pos/[M+NH4]+ & 948.7345 & \multirow{5}{*}{$5.7-6.3$} \\
\hline & $\mathrm{C} 53 \mathrm{H} 100 \mathrm{O} 13$ & pos/[M+NH4]+ & 962.7502 & \\
\hline & $\mathrm{C} 54 \mathrm{H} 102 \mathrm{O} 13$ & pos/[M+NH4]+ & 976.7658 & \\
\hline & $\mathrm{C} 55 \mathrm{H} 104 \mathrm{O} 13$ & pos/[M+NH4]+ & 990.7815 & \\
\hline & $\mathrm{C} 56 \mathrm{H} 106 \mathrm{O} 13$ & pos/[M+NH4]+ & 1004.7971 & \\
\hline \multirow{5}{*}{ mycobactins } & C46H75O10N5 & pos/[M+Fe-2H]+ & 911.4701 & \multirow{5}{*}{$6.7-6.8$} \\
\hline & C47H77010N5 & pos/[M+Fe-2H]+ & 925.4858 & \\
\hline & $\mathrm{C} 45 \mathrm{H} 71010 \mathrm{~N} 5$ & pos/[M+Fe-2H]+ & 895.4388 & \\
\hline & $\mathrm{C} 46 \mathrm{H} 73010 \mathrm{~N} 5$ & pos/[M+Fe-2H]+ & 909.4545 & \\
\hline & C47H75O10N5 & pos/[M+Fe-2H]+ & 923.4701 & \\
\hline \multirow{3}{*}{ tetraacylated sulfoglycolipids } & $\mathrm{C} 132 \mathrm{H} 254 \mathrm{O} 20 \mathrm{~S}$ & neg/[M-H]- & 2190.8506 & \multirow{3}{*}{$6.7-7.2$} \\
\hline & $\mathrm{C} 133 \mathrm{H} 256 \mathrm{O} 20 \mathrm{~S}$ & neg/[M-H]- & 2204.8663 & \\
\hline & $\mathrm{C} 134 \mathrm{H} 258 \mathrm{O} 20 \mathrm{~S}$ & neg/[M-H]- & 2218.8819 & \\
\hline
\end{tabular}


Table 1

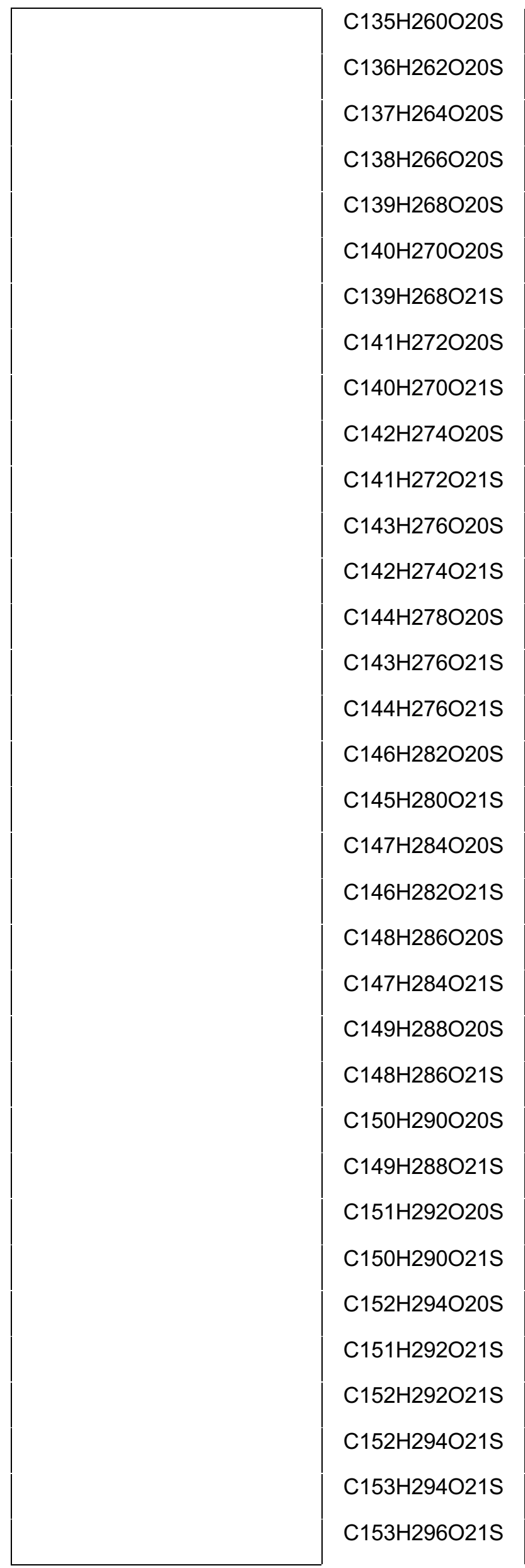

\begin{tabular}{|c|c|}
\hline neg/[M-H]- & 2232.8976 \\
\hline neg/[M-H]- & 2246.9132 \\
\hline neg/[M-H]- & 2260.9289 \\
\hline neg/[M-H]- & 2274.9445 \\
\hline neg/[M-H]- & 2288.9602 \\
\hline neg/[M-H]- & 2302.9758 \\
\hline neg/[M-H]- & 2304.9551 \\
\hline neg/[M-H]- & 2316.9915 \\
\hline neg/[M-H]- & 2318.9708 \\
\hline neg/[M-H]- & 2331.0071 \\
\hline neg/[M-H]- & 2332.9864 \\
\hline neg/[M-H]- & 2345.0228 \\
\hline neg/[M-H]- & 2347.0021 \\
\hline neg/[M-H]- & 2359.0384 \\
\hline neg/[M-H]- & 2361.0177 \\
\hline neg/[M-H]- & 2373.0177 \\
\hline neg/[M-H]- & 2387.0697 \\
\hline neg/[M-H]- & 2389.0490 \\
\hline neg/[M-H]- & 2401.0854 \\
\hline neg/[M-H]- & 2403.0647 \\
\hline neg/[M-H]- & 2415.1010 \\
\hline neg/[M-H]- & 2417.0803 \\
\hline neg/[M-H]- & 2429.1167 \\
\hline neg/[M-H]- & 2431.0960 \\
\hline neg/[M-H]- & 2443.1323 \\
\hline neg/[M-H]- & 2445.1116 \\
\hline neg/[M-H]- & 2457.1480 \\
\hline neg/[M-H]- & 2459.1273 \\
\hline neg/[M-H]- & 2471.1636 \\
\hline neg/[M-H]- & 2473.1429 \\
\hline neg/[M-H]- & 2485.1429 \\
\hline neg/[M-H]- & 2487.1586 \\
\hline neg/[M-H]- & 2499.1586 \\
\hline neg/[M-H]- & 2501.1742 \\
\hline
\end{tabular}


Table 1

\begin{tabular}{|c|c|c|c|c|}
\hline & C154H296O21S & neg/[M-H]- & 2513.1742 & \\
\hline & C154H298O21S & neg/[M-H]- & 2515.1899 & \\
\hline & $\mathrm{C} 155 \mathrm{H} 298 \mathrm{O} 21 \mathrm{~S}$ & neg/[M-H]- & 2527.1899 & \\
\hline & $\mathrm{C} 155 \mathrm{H} 300 \mathrm{O} 21 \mathrm{~S}$ & neg/[M-H]- & 2529.2055 & \\
\hline & $\mathrm{C} 156 \mathrm{H} 300 \mathrm{O} 21 \mathrm{~S}$ & neg/[M-H]- & 2541.2055 & \\
\hline & $\mathrm{C} 156 \mathrm{H} 302 \mathrm{O} 21 \mathrm{~S}$ & neg/[M-H]- & 2543.2212 & \\
\hline & $\mathrm{C} 157 \mathrm{H} 302 \mathrm{O} 21 \mathrm{~S}$ & neg/[M-H]- & 2555.2212 & \\
\hline & $\mathrm{C} 157 \mathrm{H} 304 \mathrm{O} 21 \mathrm{~S}$ & neg/[M-H]- & 2557.2368 & \\
\hline & $\mathrm{C} 158 \mathrm{H} 304 \mathrm{O} 21 \mathrm{~S}$ & neg/[M-H]- & 2569.2368 & \\
\hline & $\mathrm{C} 158 \mathrm{H} 306 \mathrm{O} 21 \mathrm{~S}$ & neg/[M-H]- & 2571.2525 & \\
\hline & $\mathrm{C} 159 \mathrm{H} 306 \mathrm{O} 21 \mathrm{~S}$ & neg/[M-H]- & 2583.2525 & \\
\hline & $\mathrm{C} 159 \mathrm{H} 308 \mathrm{O} 21 \mathrm{~S}$ & neg/[M-H]- & 2585.2681 & \\
\hline & $\mathrm{C} 160 \mathrm{H} 308 \mathrm{O} 21 \mathrm{~S}$ & neg/[M-H]- & 2597.2681 & \\
\hline & $\mathrm{C} 160 \mathrm{H} 310 \mathrm{O} 21 \mathrm{~S}$ & neg/[M-H]- & 2599.2838 & \\
\hline & $\mathrm{C} 161 \mathrm{H} 312 \mathrm{O} 21 \mathrm{~S}$ & neg/[M-H]- & 2613.2994 & \\
\hline & $\mathrm{C} 162 \mathrm{H} 312 \mathrm{O} 21 \mathrm{~S}$ & neg/[M-H]- & 2625.2994 & \\
\hline & $\mathrm{C} 162 \mathrm{H} 314 \mathrm{O} 21 \mathrm{~S}$ & neg/[M-H]- & 2627.3151 & \\
\hline & $\mathrm{C} 163 \mathrm{H} 316 \mathrm{O} 21 \mathrm{~S}$ & neg/[M-H]- & 2641.3307 & \\
\hline & $\mathrm{C} 164 \mathrm{H} 318 \mathrm{O} 21 \mathrm{~S}$ & neg/[M-H]- & 2655.3464 & \\
\hline & $\mathrm{C} 165 \mathrm{H} 320 \mathrm{O} 21 \mathrm{~S}$ & neg/[M-H]- & 2669.3620 & \\
\hline & $\mathrm{C} 166 \mathrm{H} 322 \mathrm{O} 21 \mathrm{~S}$ & neg/[M-H]- & 2683.3777 & \\
\hline & $\mathrm{C} 167 \mathrm{H} 324 \mathrm{O} 21 \mathrm{~S}$ & neg/[M-H]- & 2697.3933 & \\
\hline & $\mathrm{C} 168 \mathrm{H} 326 \mathrm{O} 21 \mathrm{~S}$ & neg/[M-H]- & 2711.4090 & \\
\hline & $\mathrm{C} 169 \mathrm{H} 328 \mathrm{O} 21 \mathrm{~S}$ & neg/[M-H]- & 2725.4246 & \\
\hline & $\mathrm{C} 170 \mathrm{H} 330 \mathrm{O} 21 \mathrm{~S}$ & neg/[M-H]- & 2739.4403 & \\
\hline & $\mathrm{C} 171 \mathrm{H} 332 \mathrm{O} 21 \mathrm{~S}$ & neg/[M-H]- & 2753.4559 & \\
\hline & $\mathrm{C} 172 \mathrm{H} 334 \mathrm{O} 21 \mathrm{~S}$ & neg/[M-H]- & 2767.4716 & \\
\hline & $\mathrm{C} 173 \mathrm{H} 336 \mathrm{O} 21 \mathrm{~S}$ & neg/[M-H]- & 2781.4872 & \\
\hline N6-tuberculosinyladenosine & $\mathrm{C} 30 \mathrm{H} 45 \mathrm{~N} 5 \mathrm{O} 4$ & $\mathrm{pos} /[\mathrm{M}+\mathrm{H}]+$ & 540.3544 & $7-8$ \\
\hline & $\mathrm{C} 102 \mathrm{H} 196 \mathrm{O} 18 \mathrm{~S}$ & neg/[M-H]- & 1740.4070 & \\
\hline triacylated sulfoglycolipids & $\mathrm{C} 102 \mathrm{H} 194 \mathrm{O} 19 \mathrm{~S}$ & neg/[M-H]- & 1754.3862 & \\
\hline & C103H196019S & neg/[M-H]- & 1768.4382 & \\
\hline
\end{tabular}


Table 1

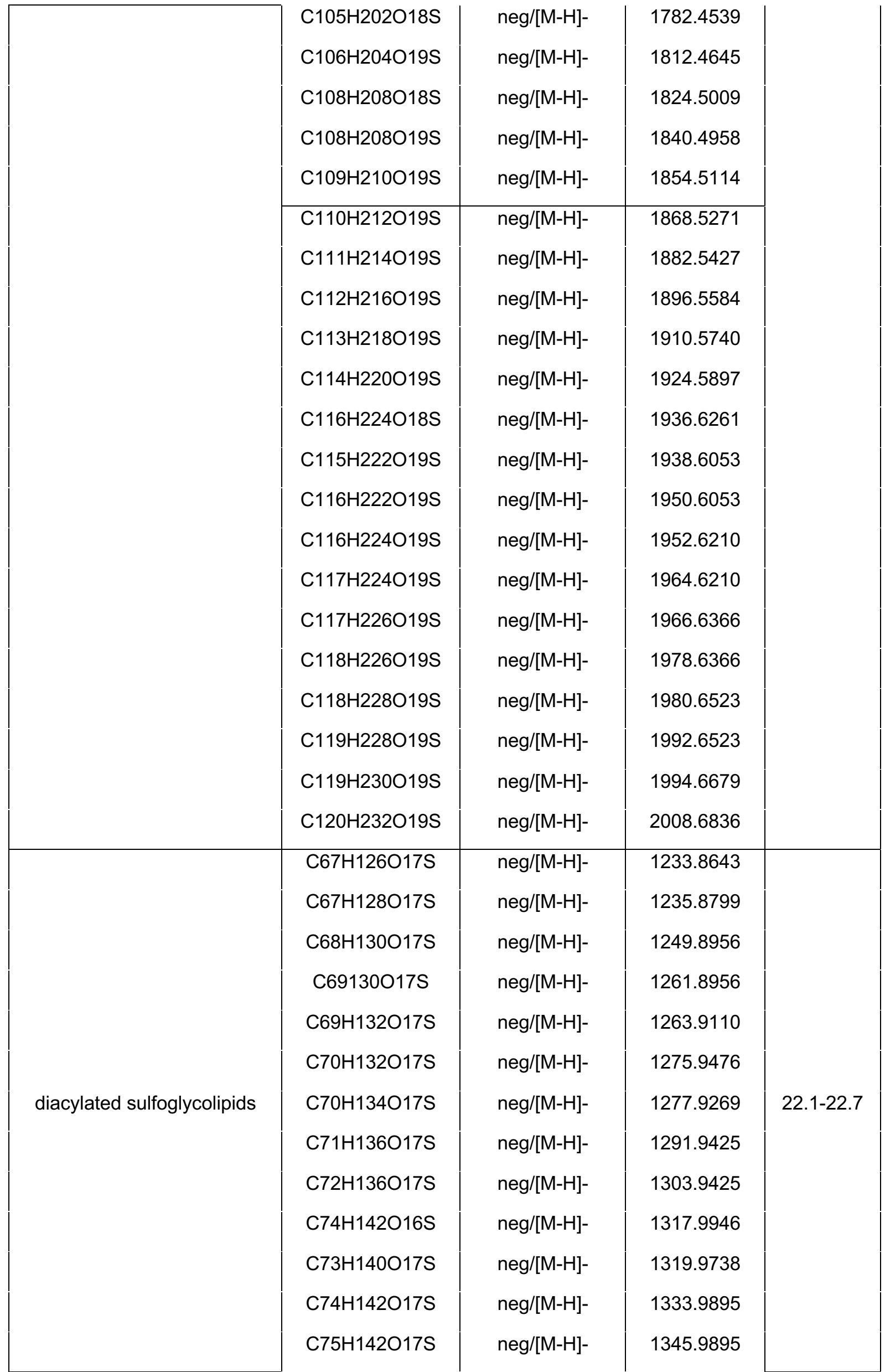


Table 1

\begin{tabular}{|c|c|c|c|c|}
\hline & $\begin{array}{l}\text { C76H144O17S } \\
\text { C76H146O17S } \\
\text { C77H148O17S }\end{array}$ & $\begin{array}{l}\text { neg/[M-H]- } \\
\text { neg/[M-H]- } \\
\text { neg/[M-H]- }\end{array}$ & $\begin{array}{l}1360.0051 \\
1362.0208 \\
1376.0364\end{array}$ & \\
\hline phosphatidylglycerol & $\begin{array}{l}\mathrm{C} 38 \mathrm{H} 73010 \mathrm{P} \\
\mathrm{C} 38 \mathrm{H} 75010 \mathrm{P} \\
\mathrm{C} 39 \mathrm{H} 77010 \mathrm{P} \\
\mathrm{C} 40 \mathrm{H} 75010 \mathrm{P} \\
\mathrm{C} 40 \mathrm{H} 77010 \mathrm{P} \\
\mathrm{C} 40 \mathrm{H} 79010 \mathrm{P} \\
\mathrm{C} 41 \mathrm{H} 79010 \mathrm{P} \\
\mathrm{C} 41 \mathrm{H} 81010 \mathrm{P} \\
\mathrm{C} 42 \mathrm{H} 79010 \mathrm{P} \\
\mathrm{C} 42 \mathrm{H} 81010 \mathrm{P} \\
\mathrm{C} 42 \mathrm{H} 83010 \mathrm{P}\end{array}$ & $\begin{array}{c}\text { neg/[M-H]- } \\
\text { neg/[M-H]- } \\
\text { neg/[M-H]- } \\
\text { neg/[M-H]- } \\
\text { neg/[M-H]- } \\
\text { neg/[M-H]- } \\
\text { neg/[M-H]- } \\
\text { neg/[M-H]- } \\
\text { neg/[M-H]- } \\
\text { neg/[M-H]- } \\
\text { neg/[M-H]- }\end{array}$ & $\begin{array}{l}719.4868 \\
721.5025 \\
735.5181 \\
745.4984 \\
747.5181 \\
749.5338 \\
761.5338 \\
763.5494 \\
773.5338 \\
775.5494 \\
777.5651\end{array}$ & $22.9-23.5$ \\
\hline 1-tuberculosinyladenosine & C30H46N5O4 & pos/[M]+ & 540.3544 & $24-25$ \\
\hline $\begin{array}{c}\text { mannosyl } \\
\text { phosphomycoketide }\end{array}$ & C38H7709P & neg/[M-H]- & 707.5196 & 24.5 \\
\hline cardiolipin & $\begin{array}{l}\text { C71H134O17P2 } \\
\text { C71H136O17P2 } \\
\text { C72H136O17P2 } \\
\text { C72H138O17P2 } \\
\text { C73H136O17P2 } \\
\text { C73H138O17P2 } \\
\text { C73H140O17P2 } \\
\text { C74H138O17P2 } \\
\text { C74H140O17P2 } \\
\text { C74H142O17P2 } \\
\text { C75H140O17P2 } \\
\text { C75H142O17P2 } \\
\text { C75H144O17P2 } \\
\text { C76H142O17P2 } \\
\text { C76H144O17P2 } \\
\text { C76H146O17P2 } \\
\text { C77H144O17P2 }\end{array}$ & $\begin{array}{l}\text { neg/[M-H]- } \\
\text { neg/[M-H]- } \\
\text { neg/[M-H]- } \\
\text { neg/[M-H]- } \\
\text { neg/[M-H]- } \\
\text { neg/[M-H]- } \\
\text { neg/[M-H]- } \\
\text { neg/[M-H]- } \\
\text { neg/[M-H]- } \\
\text { neg/[M-H]- } \\
\text { neg/[M-H]- } \\
\text { neg/[M-H]- } \\
\text { neg/[M-H]- } \\
\text { neg/[M-H]- } \\
\text { neg/[M-H]- } \\
\text { neg/[M-H]- } \\
\text { neg/[M-H]- }\end{array}$ & $\begin{array}{l}1319.9024 \\
1321.9180 \\
1333.9180 \\
1335.9337 \\
1345.9180 \\
1347.9337 \\
1349.9493 \\
1359.9337 \\
1361.9493 \\
1363.9650 \\
1373.9493 \\
1375.9650 \\
1377.9806 \\
1387.9650 \\
1389.9806 \\
1391.9963 \\
1401.9806\end{array}$ & $24.9-25.9$ \\
\hline
\end{tabular}


Table 1

\begin{tabular}{|c|c|c|c|c|}
\hline & $\begin{array}{l}\text { C77H146O17P2 } \\
\text { C77H146O17P2 } \\
\text { C78H146O17P2 } \\
\text { C78H148O17P2 } \\
\text { C78H150017P2 } \\
\text { C79H148017P2 } \\
\text { C79H150017P2 } \\
\text { C79H152O17P2 } \\
\text { C80H150017P2 } \\
\text { C80H152O17P2 } \\
\text { C80H154O17P2 } \\
\text { C81H152O17P2 } \\
\text { C81H154O17P2 } \\
\text { C81H156O17P2 } \\
\text { C82H154O17P2 } \\
\text { C82H156O17P2 } \\
\text { C82H158O17P2 } \\
\text { C83H156O17P2 } \\
\text { C83H158O17P2 } \\
\text { C83H160017P2 }\end{array}$ & $\begin{array}{l}\text { neg/[M-H]- } \\
\text { neg/[M-H]- } \\
\text { neg/[M-H]- } \\
\text { neg/[M-H]- } \\
\text { neg/[M-H]- } \\
\text { neg/[M-H]- } \\
\text { neg/[M-H]- } \\
\text { neg/[M-H]- } \\
\text { neg/[M-H]- } \\
\text { neg/[M-H]- } \\
\text { neg/[M-H]- } \\
\text { neg/[M-H]- } \\
\text { neg/[M-H]- } \\
\text { neg/[M-H]- } \\
\text { neg/[M-H]- } \\
\text { neg/[M-H]- } \\
\text { neg/[M-H]- } \\
\text { neg/[M-H]- } \\
\text { neg/[M-H]- } \\
\text { neg/[M-H]- }\end{array}$ & $\begin{array}{l}1403.9963 \\
1406.0119 \\
1415.9963 \\
1418.0119 \\
1420.0276 \\
1430.0119 \\
1432.0276 \\
1434.0432 \\
1444.0276 \\
1446.0432 \\
1448.0589 \\
1458.0432 \\
1460.0589 \\
1462.0745 \\
1472.0589 \\
1474.0745 \\
1476.0902 \\
1486.0745 \\
1488.0902 \\
1490.1058\end{array}$ & \\
\hline 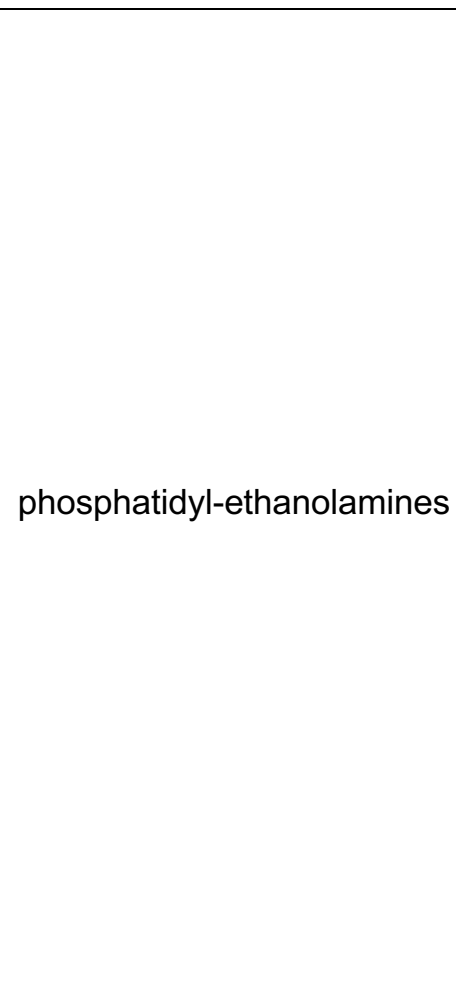 & $\begin{array}{l}\mathrm{C} 35 \mathrm{H} 70 \mathrm{O} \mathrm{NP} \\
\mathrm{C} 36 \mathrm{H} 72 \mathrm{O} 8 \mathrm{NP} \\
\mathrm{C} 37 \mathrm{H} 72 \mathrm{O} 8 \mathrm{NP} \\
\mathrm{C} 37 \mathrm{H} 7408 \mathrm{NP} \\
\mathrm{C} 38 \mathrm{H} 7408 \mathrm{NP} \\
\mathrm{C} 35 \mathrm{H} 66 \mathrm{O} 8 \mathrm{NP} \\
\mathrm{C} 39 \mathrm{H} 7408 \mathrm{NP} \\
\mathrm{C} 39 \mathrm{H} 76 \mathrm{O} \mathrm{NP} \\
\mathrm{C} 39 \mathrm{H} 78 \mathrm{O} \mathrm{NP} \\
\mathrm{C} 40 \mathrm{H} 78 \mathrm{O} \mathrm{NP} \\
\mathrm{C} 40 \mathrm{H} 8008 \mathrm{NP} \\
\mathrm{C} 41 \mathrm{H} 8008 \mathrm{NP} \\
\mathrm{C} 41 \mathrm{H} 82 \mathrm{O} \mathrm{NP} \\
\mathrm{C} 42 \mathrm{H} 84 \mathrm{O} 8 \mathrm{NP}\end{array}$ & $\begin{array}{c}\text { neg/[M-H]- } \\
\text { neg/[M-H]- } \\
\text { neg/[M-H]- } \\
\text { neg/[M-H]- } \\
\text { neg/[M-H]- } \\
\text { neg/[M-H]- } \\
\text { neg/[M-H]- } \\
\text { neg/[M-H]- } \\
\text { neg/[M-H]- } \\
\text { neg/[M-H]- } \\
\text { neg/[M-H]- } \\
\text { neg/[M-H]- } \\
\text { neg/[M-H]- } \\
\text { neg/[M-H]- }\end{array}$ & $\begin{array}{l}662.4766 \\
676.4923 \\
688.4923 \\
690.5079 \\
702.5079 \\
704.5236 \\
714.5079 \\
716.5236 \\
718.5392 \\
730.5392 \\
732.5549 \\
744.5549 \\
746.5705 \\
760.5862\end{array}$ & 更 \\
\hline
\end{tabular}


Table 1

\begin{tabular}{|c|c|c|c|c|}
\hline & $\begin{array}{l}\text { C43H86O8NP } \\
\text { C44H84O8NP } \\
\text { C44H86O8NP }\end{array}$ & $\begin{array}{l}\text { neg/[M-H]- } \\
\text { neg/[M-H]- } \\
\text { neg/[M-H]- }\end{array}$ & $\begin{array}{l}774.6018 \\
784.5862 \\
786.6018\end{array}$ & \\
\hline phosphatidylinositols & $\begin{array}{l}\text { C41H79O13P } \\
\text { C42H81013P } \\
\text { C43H79013P } \\
\text { C43H81013P } \\
\text { C43H83013P } \\
\text { C44H83013P } \\
\text { C44H85O13P } \\
\text { C45H85O13P } \\
\text { C45H87013P } \\
\text { C46H87013P } \\
\text { C46H89013P }\end{array}$ & $\begin{array}{c}\text { neg/[M-H]- } \\
\text { neg/[M-H]- } \\
\text { neg/[M-H]- } \\
\text { neg/[M-H]- } \\
\text { neg/[M-H]- } \\
\text { neg/[M-H]- } \\
\text { neg/[M-H]- } \\
\text { neg/[M-H]- } \\
\text { neg/[M-H]- } \\
\text { neg/[M-H]- } \\
\text { neg/[M-H]- }\end{array}$ & $\begin{array}{l}809.5186 \\
823.5342 \\
833.5186 \\
835.5342 \\
837.5499 \\
849.5499 \\
851.5655 \\
863.5655 \\
865.5812 \\
877.5812 \\
879.5968\end{array}$ & $26.2-27.4$ \\
\hline $\begin{array}{l}\text { lysophosphatidyl } \\
\text { ethanolamines }\end{array}$ & $\begin{array}{l}\mathrm{C} 23 \mathrm{H} 48 \mathrm{O} 7 \mathrm{NP} \\
\mathrm{C} 24 \mathrm{H} 50 \mathrm{O} \mathrm{NP} \\
\mathrm{C} 25 \mathrm{H} 52 \mathrm{O} 7 \mathrm{NP}\end{array}$ & $\begin{array}{l}\text { neg/[M-H]- } \\
\text { neg/[M-H]- } \\
\text { neg/[M-H]- }\end{array}$ & $\begin{array}{l}480.3096 \\
494.3252 \\
508.3409\end{array}$ & $30.7-31.9$ \\
\hline lysophosphatidyl-inositols & $\begin{array}{l}\mathrm{C} 25 \mathrm{H} 49012 \mathrm{P} \\
\mathrm{C} 27 \mathrm{H} 53012 \mathrm{P} \\
\mathrm{C} 28 \mathrm{H} 55012 \mathrm{P}\end{array}$ & $\begin{array}{l}\text { neg/[M-H]- } \\
\text { neg/[M-H]- } \\
\text { neg/[M-H]- }\end{array}$ & $\begin{array}{l}571.2889 \\
599.3202 \\
613.3359\end{array}$ & 32.2 \\
\hline $\begin{array}{l}\text { diacyl phosphatidylinositol } \\
\text { dimannoside (PIM2Ac2) }\end{array}$ & $\begin{array}{l}\text { C88H165O25P } \\
\text { C90H169O25P } \\
\text { C91H171O25P }\end{array}$ & $\begin{array}{l}\text { neg/[M-H]- } \\
\text { neg/[M-H]- } \\
\text { neg/[M-H]- }\end{array}$ & $\begin{array}{l}1652.1304 \\
1680.1617 \\
1694.1774\end{array}$ & 25.6 \\
\hline $\begin{array}{c}\text { monoacyl } \\
\text { phosphatidylinositol } \\
\text { trimannosides (PIM3Ac1) }\end{array}$ & $\begin{array}{l}\mathrm{C} 78 \mathrm{H} 145 \mathrm{O} 29 \mathrm{P} \\
\mathrm{C} 80 \mathrm{H} 149 \mathrm{O} 29 \mathrm{P}\end{array}$ & $\begin{array}{l}\text { neg/[M-H]- } \\
\text { neg/[M-H]- }\end{array}$ & $\begin{array}{l}1575.9536 \\
1603.9849\end{array}$ & 32.1 \\
\hline $\begin{array}{c}\text { monoacyl } \\
\text { phosphatidylinositol } \\
\text { dimannosides (PIM2Ac1) }\end{array}$ & $\begin{array}{l}\mathrm{C} 72 \mathrm{H} 135 \mathrm{O} 24 \mathrm{P} \\
\mathrm{C} 74 \mathrm{H} 139 \mathrm{O} 24 \mathrm{P}\end{array}$ & $\begin{array}{l}\text { neg/[M-H]- } \\
\text { neg/[M-H]- }\end{array}$ & $\begin{array}{l}1413.9008 \\
1441.9321\end{array}$ & 32.1 \\
\hline $\begin{array}{l}\text { phosphatidyl inositol } \\
\text { dimannoside (PIM2) }\end{array}$ & $\begin{array}{l}\text { C53H99O23P } \\
\text { C56H105O23P }\end{array}$ & $\begin{array}{l}\text { neg/[M-H]- } \\
\text { neg/[M-H]- }\end{array}$ & $\begin{array}{l}1133.6241 \\
1175.6711\end{array}$ & 32.5 \\
\hline $\begin{array}{c}\text { monoacyl } \\
\text { phosphatidylinositol } \\
\text { hexamannoside (PIM6Ac1) }\end{array}$ & $\begin{array}{l}\text { C96H175O44P } \\
\text { C98H179O44P }\end{array}$ & $\begin{array}{l}\text { neg/[M-H]- } \\
\text { neg/[M-H]- }\end{array}$ & $\begin{array}{l}2062.1121 \\
2090.1434\end{array}$ & 37.8 \\
\hline $\begin{array}{l}\text { diacyl phosphatidylinositol } \\
\text { hexamannoside (PIM6Ac2) }\end{array}$ & $\begin{array}{l}\text { C114H209O45P } \\
\text { C115H211045P }\end{array}$ & $\begin{array}{l}\text { neg/[M-H]- } \\
\text { neg/[M-H]- }\end{array}$ & $\begin{array}{l}2328.3730 \\
2342.3887\end{array}$ & 37.5 \\
\hline
\end{tabular}


Table 1 